This item was submitted to Loughborough's Research Repository by the author.

Items in Figshare are protected by copyright, with all rights reserved, unless otherwise indicated.

\title{
Temperature-dependent mechanical behaviour of PMMA: Experimental analysis and modelling
}

\section{PLEASE CITE THE PUBLISHED VERSION}

http://dx.doi.org/10.1016/j.polymertesting.2016.12.016

\section{PUBLISHER}

(c) Elsevier

\section{VERSION}

AM (Accepted Manuscript)

\section{PUBLISHER STATEMENT}

This work is made available according to the conditions of the Creative Commons Attribution-NonCommercialNoDerivatives 4.0 International (CC BY-NC-ND 4.0) licence. Full details of this licence are available at: https://creativecommons.org/licenses/by-nc-nd/4.0/

\section{LICENCE}

CC BY-NC-ND 4.0

\section{REPOSITORY RECORD}

Abdel-Wahab, Adel A., Sabbah Ataya, and Vadim V. Silberschmidt. 2019. "Temperature-dependent Mechanical Behaviour of PMMA: Experimental Analysis and Modelling”. figshare. https://hdl.handle.net/2134/23887. 


\title{
Temperature-dependent mechanical behaviour of PMMA: Experimental analysis and modelling
}

\author{
Adel A. Abdel-Wahab ${ }^{\text {a, c, * , Sabbah Ataya }}{ }^{\text {b, c }}$, Vadim V. Silberschmidt ${ }^{\mathrm{d}}$ \\ ${ }^{a}$ Mechanical Engineering Department, Faculty of Engineering, Alexandria University, Alexandria, 21544, Egypt \\ ${ }^{\mathrm{b}}$ Department of Metallurgy and Materials Engineering, Faculty of Petroleum and Mining Engineering, Suez University, Suez, 43721, Egypt \\ ${ }^{c}$ Mechanical Engineering Department, College of Engineering, Al Imam Mohammad Ibn Saud Islamic University, Riyadh 11432, Saudi Arabia \\ ${ }^{\mathrm{d}}$ Wolfson School of Mechanical, Electrical and Manufacturing Engineering, Loughborough University, Loughborough Leicestershire LE11 $3 T$,
}

$U K$

\begin{abstract}
A B S T R A C T
An experimental study of temperature-dependent mechanical behaviour of Poly-methyl methacrylate (PMMA) was performed at a range of temperatures $\left(20^{\circ} \mathrm{C}, 40^{\circ} \mathrm{C}, 60^{\circ} \mathrm{C}\right.$ and $\left.80{ }^{\circ} \mathrm{C}\right)$ below its glass transition point $\left(108{ }^{\circ} \mathrm{C}\right)$ under uniaxial tension and three-point bending loading conditions. This study was accompanied by simulations aimed at identification of material parameters for two different constitutive material models. Experimental flow curves obtained for PMMA were used in elasto-plastic analysis, while a sim-flow optimization tool was employed for a two-layer viscoplasticity model. The temperature increase significantly affected mechanical behaviour of PMMA, with quasi-brittle fracture at room temperature and super-plastic behaviour $(\varepsilon>110 \%)$ at $80{ }^{\circ} \mathrm{C}$. The two-layer viscoplasticity material model was found to agree better with the experimental data obtained for uniaxial tension than the elasto-plastic description.
\end{abstract}

\author{
Keywords: \\ Poly (methyl methacrylate) \\ Uniaxial tension \\ Three-point bending \\ Temperature dependence \\ Finite element \\ Two-layer viscoplasticity
}

\section{Introduction}

Poly-methyl methacrylate (PMMA) is an amorphous thermoplastic with moderate mechanical properties at room temperature and strain rate of $10^{-3} \mathrm{~s}^{-1}$ : tensile strength $\left(\sigma_{U T S}\right)$ of $70 \mathrm{MPa}$, elastic modulus $(\boldsymbol{E})$ of $3300 \mathrm{MPa}$ and low density as compared to metallic materials: $\rho=1.19 \mathrm{~g} \mathrm{~cm}^{-3}$. Importantly, PMMA is biocompatible, making it highly desirable for use in electronics, micro-electromechanical systems (MEMS), biomedical, micro-optics and microfluidic devices [1].

In many of its applications, PMMA is exposed to a wide range of environmental and loading conditions [2]. Hence, several experimental studies were carried out to characterize its mechanical behaviour in terms of temperature and strain-rate sensitivity [3-5]. In particular, various studies investigated response of PMMA to quasi-static and dynamic conditions. For instance, Arruda et al. [6] analyzed the effect of temperature on compression of PMMA in quasi-static and intermediate strain-rate regions. They found that

\footnotetext{
* Corresponding author. Mechanical Engineering Department, Faculty of Engineering, Alexandria University, Alexandria, 21544, Egypt.

E-mail address: a.a.abdel-wahab@alexu.edu.eg (A.A. Abdel-Wahab).
}

softening of the material occurring after its yield was a combined effect of strain hardening/softening and thermal softening. Also, Richeton et al. [7] studied the effect of a wide range of strain rates (from $0.0001 \mathrm{~s}^{-1}$ up to $5000 \mathrm{~s}^{-1}$ ) and temperatures (from $-40{ }^{\circ} \mathrm{C}$ up to $180{ }^{\circ} \mathrm{C}$ ) on mechanical response using compression tests. They found that yield stress increased with decreasing temperature and increasing strain rate for the studied materials including PMMA. Similar analysis for yield stress was performed by Chou et al. [8] and Briscoe and Nosker [9]. More recently, Jancar et al. [10] studied the effect of temperature and strain rate on yield stresses and post-yield softening of PMMA. Additionally, Raha and Bowsen [11] conducted plane-strain compression tests on PMMA to study the structural changes employing birefringence measurements. They reported that the model of dissociable cohesion points gave a reasonable explanation to all the observations on the polymer for its optical and mechanical properties. Arruda and Boyce [12] also performed uniaxial and plane-strain compression tests at temperatures below the glass transition to study the effect of anisotropy on deformation; stress-strain behaviour was found to depend strongly on the state of deformation.

Dissimilar to metallic materials, PMMA demonstrates initial yielding that depends on pressure, strain rate and temperature, but true strain softening after yielding, i.e., a drop in level of true stress 


\begin{tabular}{|c|c|c|}
\hline \multicolumn{2}{|c|}{ Nomenclature } & $\begin{array}{l}A, m, n \text { Norton-Hoff rate parameters } \\
b, h_{0}, h_{1}, m_{1}, m_{2}, w, \sigma_{1}, \sigma_{2} \text { Material parameters }\end{array}$ \\
\hline$B$ & Width of specimen & Tensile strength \\
\hline$c_{\mathrm{Y}}, c_{\mathrm{UTS}}$ & Material constants & True strain \\
\hline$d$ & Specimen's deflection at mid-span & Strain rate \\
\hline E & Elastic modulus & Reference strain rate \\
\hline$e$ & Engineering strain & Flexure strain \\
\hline$F$ & Applied force & Strain at fracture \\
\hline$f$ & Ratio of elastic modulus of elastic network $\left(K_{v}\right)$ to total & Total strain \\
\hline & (instantaneous) modulus $\left(K_{p}+K_{v}\right)$ & Steady-state creep rate \\
\hline$H^{\prime}$ & Hardening parameter & Poisson's ratio \\
\hline$h$ & Thickness of specimen & Density \\
\hline$K$ & Elastic modulus of material at highest loading rate & Engineering stress \\
\hline$K_{p}$ & Modulus of elastic-plastic network & True stress \\
\hline$K_{v}$ & Modulus of elastic-viscous network & Proof stress \\
\hline$l$ & Beam span & Flexure stress \\
\hline$S$ & Slope of force-deflection curve & Flow stress \\
\hline$T$ & Test temperature & Stress in elastic-plastic network \\
\hline$T_{0}$ & Reference temperature (room temperature) & Total stress \\
\hline$T_{\mathrm{g}}$ & Glass transition temperature & Stress in elastic-viscous network \\
\hline U1 & Translation in $\mathrm{x}$-axis & $\sigma_{\mathrm{Y}}, \sigma_{\mathrm{UTS}}$ Yield stress and ultimate tensile stress \\
\hline $\mathrm{U} 2$ & Translation in y-axis & \multirow{3}{*}{$\begin{array}{c}\sigma_{0_{\mathrm{Y}}}, \sigma_{0_{\text {UTS }}} \text { Yield stress and ultimate tensile stress at reference } \\
\text { temperature } T_{0}\end{array}$} \\
\hline UR1 & Rotation about $\mathrm{x}$-axis & \\
\hline UR2 & Rotation about y-axis & \\
\hline
\end{tabular}

with plastic straining can be observed. At large strains, the material hardens [13] (more information about the true stress - true strain response of PMMA can be found in Refs. [6,13]). This feature of stress - strain curves of PMMA makes it cumbersome to model.

Various material models have been suggested in the literature to describe amorphous polymers; their main application is to simulate different processing techniques [14]. There are many efforts to provide a constitutive model to capture mechanical behaviour of PMMA. Some of the early works on modelling of glassy polymers developed by many researchers can be found in Refs. [15-20].

This work focuses on analysis of the temperature-dependent behaviour of PMMA and applicability of two constitutive models elastic-plastic and two-layer viscoplastic - available in Abaqus 6.13 finite-element software. Tensile and bending tests of PMMA were performed over an application-relevant temperature range $\left(20^{\circ} \mathrm{C}\right.$, $40^{\circ} \mathrm{C}, 60^{\circ} \mathrm{C}$ and $80^{\circ} \mathrm{C}$ ) below its glass transition point $\left(108^{\circ} \mathrm{C}\right)$. The obtained experimental data were used to quantify parameters of the two constitutive models.

To the best of the authors' knowledge, this is the first study aimed at identification of parameters for two different material formulations of PMMA using an optimization simulation process flow 'sim-flow'.

\section{Experimental procedure}

\subsection{Materials and manufacturing process}

The material used in this study was standard-grade MD001 commercial poly (methyl methacrylate) (PMMA) with mass density of $1.19 \mathrm{~g} / \mathrm{cm}^{3}$ at room temperature. PMMA samples for tension and bending were produced using a multipurpose injection moulding machine Arburg Allrounder 420 C, Golden Edition (Lossburg, Germany) in a sample set mould containing different specimens with their standard dimensions. This process was implemented according to standard ISO 8257 [21].

Dimensions of tensile test samples were according to BS 2782-3 $[22,23]$ or ISO 527 [23]. Dumbbell tensile-test specimens had a total length of $170 \mathrm{~mm}$, width of $10 \mathrm{~mm}$ for the middle section and a thickness of $4 \mathrm{~mm}$. Three-point bending specimens were prepared and produced according to ISO 178 [24] with a total length of $80 \mathrm{~mm}$, a width of $10 \mathrm{~mm}$ and a thickness of $4 \mathrm{~mm}$.

\subsection{Uniaxial tension test}

Tensile tests of the PMMA were performed using an Instron 3367 system with a maximum load capacity of $30 \mathrm{kN}$ equipped with an environmental chamber with a temperature range from -70 to $350^{\circ} \mathrm{C}$ and feedback temperature control. Before a test, the chamber was preheated to the designated temperature and left until the temperature became stable. Then, each specimen was mounted and left for $5 \mathrm{~min}$ in the chamber to reach the desired temperature, see Fig. 1.

The tensile tests on PMMA were carried out at temperatures of $20^{\circ} \mathrm{C}, 40^{\circ} \mathrm{C}, 60{ }^{\circ} \mathrm{C}$ and $80^{\circ} \mathrm{C}$. In order to perform the test with a strain rate of $0.001 \mathrm{~s}^{-1}$, the speed of the crosshead was adjusted to $0.08 \mathrm{~mm} / \mathrm{s}$. Two specimens were tested for each temperature.

\subsection{Three-point bending test}

Three-point bending tests were performed using a universal testing machine Zwick/Roell Z100 with a $100 \mathrm{kN}$ load cell. A pair of supports was manufactured using tool steel (Fig. 2); the span between the lower supports $\boldsymbol{l}$ was adjusted at $64 \mathrm{~mm}$ and the loading speed was $3 \mathrm{~mm} / \mathrm{min}$.

Three-point bending tests were performed at the same temperatures as tensile tests. A dedicated heating chamber was built, with temperature measured with a thermocouple near the middle section of the specimen; a supply of hot air and temperature level were manually controlled. The test was performed either until fracture of the specimen or reaching a deflection of 0.7 of a half span length. Here, also, two specimens were tested for each temperature. 


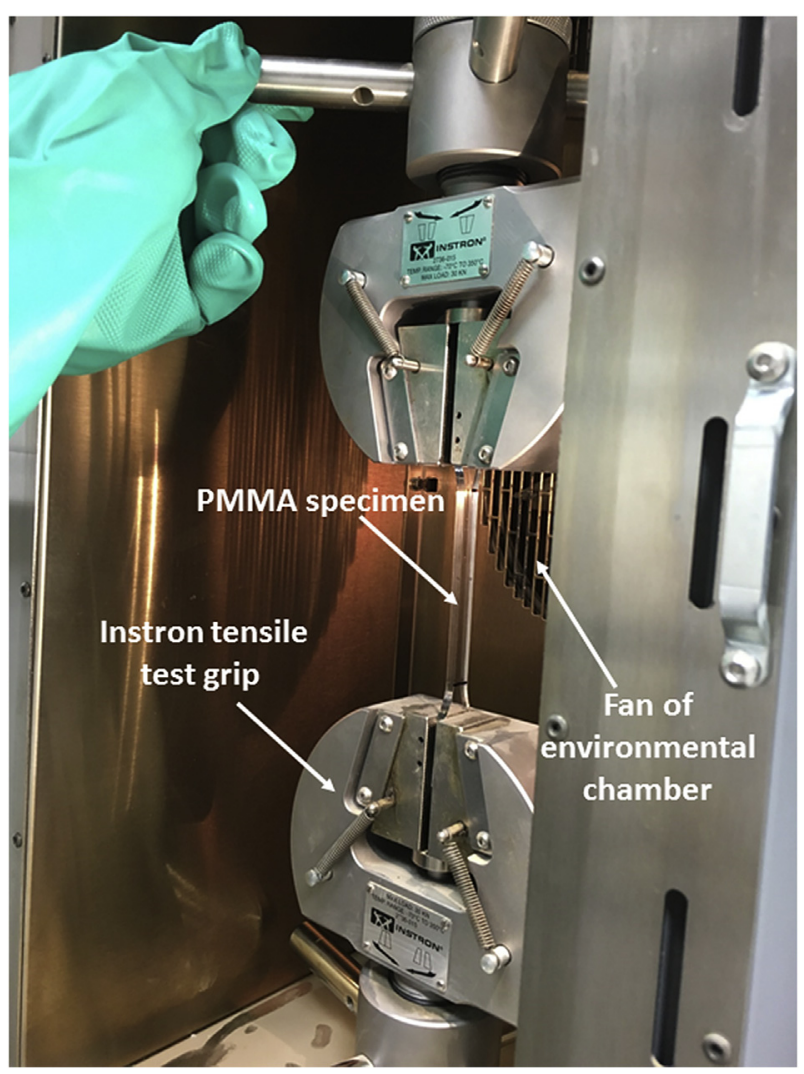

Fig. 1. Tensile-test specimen mounted in grips of Instron 3367 inside environmental chamber.

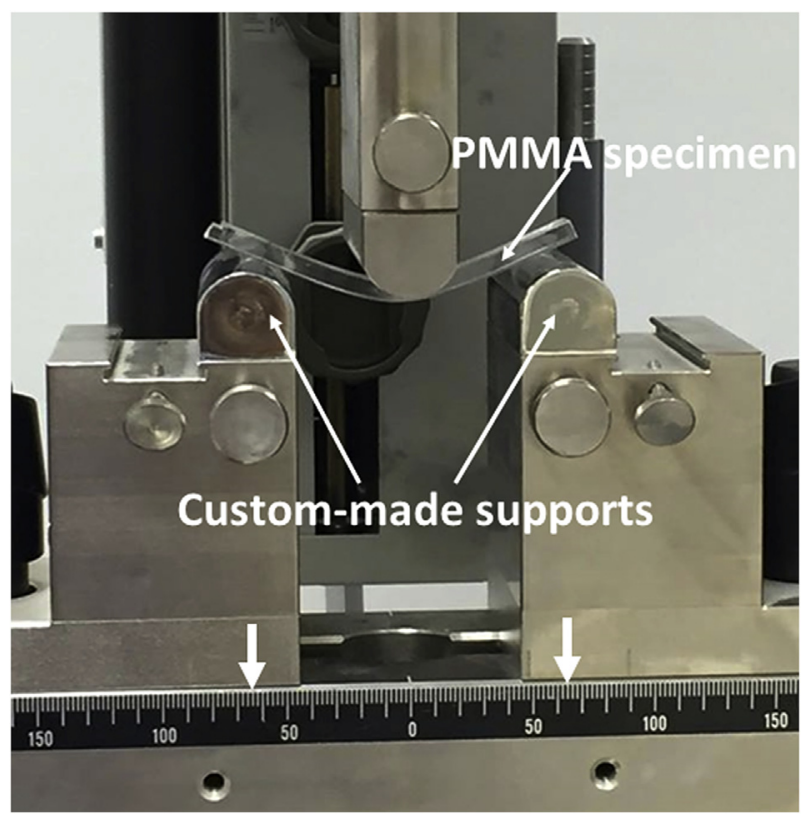

Fig. 2. Three-point bending specimen mounted on custom-made supports during test.

\section{Finite-element modelling}

\subsection{Model uniaxial tension test}

A tensile FE model was used to identify material parameters for two material formulations for PMMA.

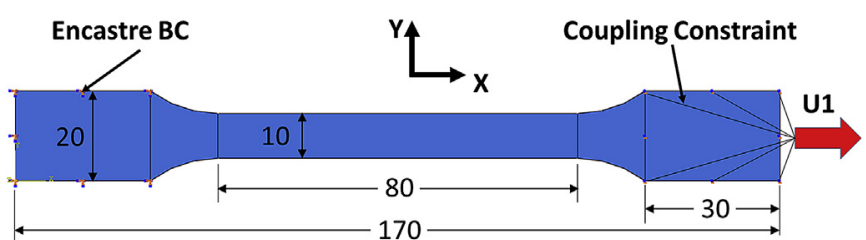

a)

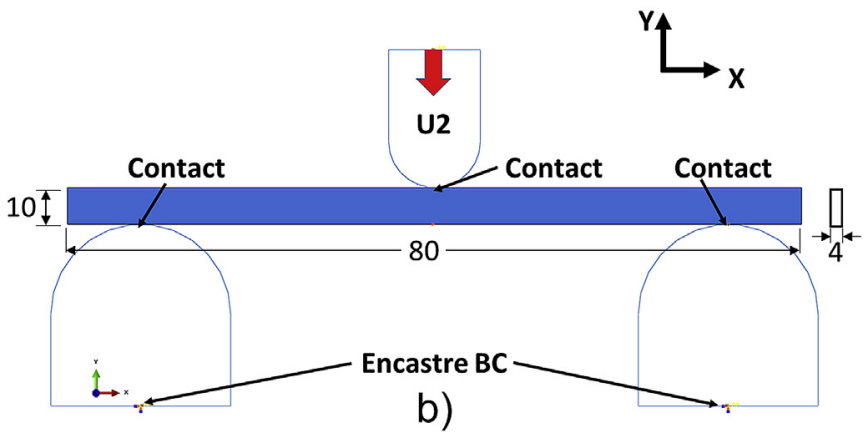

Fig. 3. 2D plain-stress finite-element model of uniaxial tension (a) and three-point bending (b) test PMMA specimen.

The geometry and dimensions of the dumbbell specimen of uniaxial tension test of PMMA were used in a two-dimensional (2D) finite-element model (FEM) developed using commercial finiteelement software ABAQUS 6.13. Following the setup of the uniaxial tension test, encastre boundary conditions $(\mathrm{U} 1=\mathrm{U} 2=\mathrm{UR} 1=\mathrm{UR} 2=0$ ) were applied to fix the left-hand part of the specimen, whereas a ramp type displacement (U1) was applied to its right-hand part (Fig. 3a). The latter was applied employing a coupling constraint between a reference point (RP) and the surface of the part, as shown in Fig. 3a; this allows all the nodes on this surface to move with the same displacement. Thanks to the symmetry of the specimen and its deformation about the x-axis, only its top-half was modelled, and a symmetry boundary condition about $\mathrm{x}$-axis was applied.

Various initial mesh sizes and element types were employed to reproduce the experimental stress-strain response obtained in the uniaxial tension tests. A number of the proposed mesh sizes and element types overestimated this response. Suitable results were obtained for an element type CPS8R, with a total number of 602 elements (1994 nodes); the average element size was $2 \mathrm{~mm}$. The simulation used a static general step with a dissipated energy fraction of 0.0002 and an adaptive stabilization with a maximum ratio of stabilization to strain energy of 0.05 .

\subsection{Model of three-point bending}

A 2D FEM of three-point bending was developed with geometry and dimensions exactly as those used in the experimental part of this study, see Fig. 3b.

The PMMA specimen was modelled as a deformable material while the supports were rigid. Following the test setup, the bottom supports were fixed using an encastre type of boundary conditions, whereas a ramp-type displacement (U2) at the reference point was applied to the top support (Fig. 3b). A surface-to-surface contact was defined between the top surface of the PMMA specimen and the outer surface of the top support; the same type of contact was applied between the bottom surface of the specimen and the outer surfaces of the bottom supports. A coefficient of friction of 0.3 was defined for all the contact surfaces for tangential behaviour and a hard contact was defined for the normal one [25]. 
In this simulation, the same mesh-sensitivity approach introduced in the uniaxial tension test model was followed for the threepoint bending model. The element type used for the PMMA specimen was CPE8RH (plain-strain quadratic with hybrid formulation), with a total number of 1280 elements (4177 nodes); the average element size was $0.5 \mathrm{~mm}$. Increments were defined as in the uniaxial-tension-test model.

\subsection{Constitutive material models for FEM}

Two material models implemented in Abaqus 6.13 [26] were employed to characterize behaviour of PMMA. The first was an elastic-plastic constitutive material model and the second a twolayer viscoplasticity model. Parameters of the former were calculated based on the experimentally obtained flow curves while for the latter they were obtained using an optimization sim-flow tool, (its details are presented below).

\section{Results and discussion}

\subsection{Uniaxial tension test}

The tension results obtained for the quasi-static strain rate of $0.001 \mathrm{~s}^{-1}$ and various temperatures below the glass transition temperature showed a significant effect of temperature on mechanical behaviour of PMMA. Its Young's modulus, yield stress, ultimate tensile stress and strain at fracture were strongly affected by increasing temperature, as evident from stress-strain responses in Fig. 4. Importantly, engineering stress-strain curves of two specimens obtained at each temperature are almost identical. Mechanical behaviour of PMMA in tensile tests exhibited an initial elastic response followed by yielding, strain softening and, finally, non-linear strain hardening, as described by Ref. [27]. As also reported in other studies, polymer glasses deformed beyond their yield stress underwent a drop in the stress level known as strain softening or yield-drop $[10,28]$. Strain softening corresponds to the onset of strain localization, and plays a critical role in controlling ultimate mechanical properties of polymers.

While the material showed almost brittle fracture with a limited strain of only $5 \%$ at room temperature, it demonstrated superplastic behaviour at $80{ }^{\circ} \mathrm{C}$, achieving strain over $110 \%$ without fracture (the test was stopped due to reaching the dimensions of the heating furnace). Also, as temperature increased, the stress corresponding to the onset of softening decreased.

The material had high ultimate tensile stress (UTS) at $20^{\circ} \mathrm{C}$, demonstrating an inverse relation with temperature, see Fig. 5. When the temperature increased from the room temperature to $80^{\circ} \mathrm{C}$, the UTS decreased by $33.7 \%$. In addition, fracture energy (area under the curve) of PMMA had increased significantly with

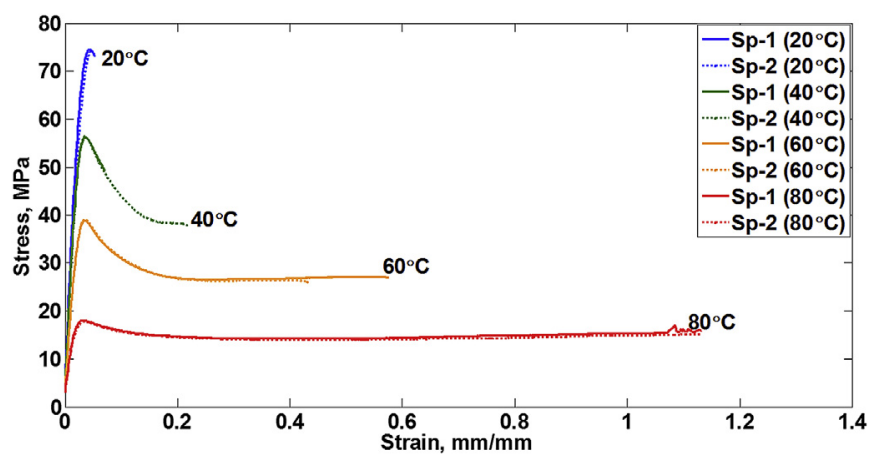

Fig. 4. Tensile stress-strain curves of PMMA at different temperatures.

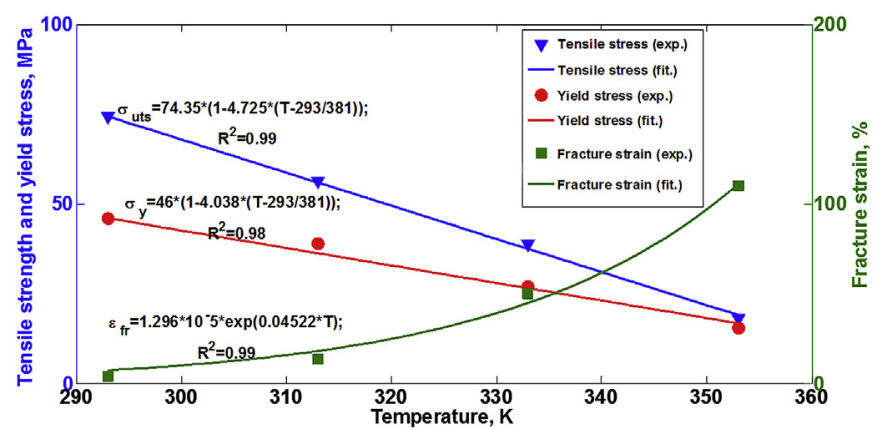

Fig. 5. Effect of temperature on material parameters (an average of two data points) for PMMA.

increasing temperature up to $60^{\circ} \mathrm{C}$ (Fig. 4).

To describe the effect of temperature on yield stress, or ultimate tensile stress, the following relationship [29] was used:

$\sigma_{\mathrm{UTS}}=\boldsymbol{\sigma}_{0_{\mathrm{UTS}}}\left(1-\boldsymbol{c}_{\mathrm{UTS}}\left(\boldsymbol{T}-\boldsymbol{T}_{0}\right) / \boldsymbol{T}_{\mathbf{g}}\right)$

$\sigma_{\mathbf{Y}}=\sigma_{0 \mathbf{Y}}\left(1-c_{\mathbf{Y}}\left(\boldsymbol{T}-\boldsymbol{T}_{0}\right) / \boldsymbol{T}_{\mathbf{g}}\right)$

where $\sigma_{\mathbf{Y}}$ and $\sigma_{\mathbf{U T S}}$ are the yield stress and the ultimate tensile stress, respectively, $\sigma_{0_{\mathrm{Y}}}$ and $\boldsymbol{\sigma}_{0_{\mathrm{urs}}}$ are the respective stress at the reference temperature $\boldsymbol{T}_{0}$ (here: room temperature in $\mathrm{K}$ ), $\boldsymbol{T}$ is the test temperature (in $\mathrm{K}$ ), $\boldsymbol{T}_{\mathbf{g}}$ is the (glass transition temperature; $381 \mathrm{~K}$ ) and $\boldsymbol{c}_{\mathbf{Y}}$ and $\boldsymbol{c}_{\mathbf{u t s}}$ are the material constants.

The yield stress (calculated here as proof stress $\sigma_{0.2 \%}$ ) exhibited behaviour similar to that of the UTS with PMMA having the highest yield stress at room temperature. Over the studied temperature range, the yield stress decreased by $67.7 \%$. It is worth mentioning that various researchers found that yield stress, ultimate tensile strength and Young's modulus decreased with increasing temperature $[27,30]$.

The strain at fracture $\boldsymbol{\varepsilon}_{\mathbf{f r}}$ (characterising an extent of elongation of the specimen elongated to failure) demonstrated different behaviour described with an exponential regression model:

$\boldsymbol{\varepsilon}_{\mathbf{f r}}=1.296 * 10^{-5} * \boldsymbol{e}^{0.04522 \boldsymbol{T}}$

It is worth mentioning that linear reduction in tensile properties (elastic modulus, yield strength and tensile strength) with temperature was observed both below and above the glass transition point of four different types of thermoplastic composites. It was noted that two different slopes were identified for variations of strength and stiffness below and above the glass transition point of $30 \mathrm{wt} \%$ short-glass-fibre-reinforced polyamide-6.6 [31]. Near $T_{g}$, a drastic reduction in tensile strength and elastic modulus was found [32].

\subsection{Three-point bending test}

The load-deflection curves obtained in bending were converted into stress-strain curves using the following equations for flexure stress $\boldsymbol{\sigma}_{\boldsymbol{b}}$ and strain $\boldsymbol{\varepsilon}_{\boldsymbol{b}}$ [24]:

$\sigma_{\boldsymbol{b}}=\frac{3 \boldsymbol{F l}}{2 \boldsymbol{B h ^ { 2 }}}$

$\varepsilon_{\boldsymbol{b}}=\frac{6 h d}{\boldsymbol{l}^{2}}$

where $\boldsymbol{h}$ and $\boldsymbol{B}$ are the thickness and width of the specimen, $\boldsymbol{F}$ is the 
force, $\boldsymbol{l}$ is the beam's span and $\boldsymbol{d}$ is the specimen's deflection at midspan.

In fact, the classical formula used to calculate bending stress (Eq. (3)) holds only in the case of ideal three-point bending for certain ratios of $l / h$, which is equal to 20 [33]. Application of this equation assumes a cross-section symmetrical about the loading axis and that the plane sections remain undistorted and normal to the long axis in loading, i.e., ignoring shear deformation. In this study $l / h$ is 20; therefore, these equations should work reasonably well.

The stress - strain curves for PMMA at different temperatures for three-point bending are presented in Fig. 6; similar to the uniaxial tension test, PMMA demonstrated high sensitivity to temperature. Almost brittle fracture behaviour was revealed at the room temperature, with minimal post yield deformation. However, when the temperature was increased incrementally by $20^{\circ} \mathrm{C}$, its effect started to become apparent, especially at $80^{\circ} \mathrm{C}$. Specimens tested for each temperature revealed similar behaviour; however, due to the high sensitivity of the material at high temperatures, the manual control used in heating resulted in small fluctuations in the responses at $60{ }^{\circ} \mathrm{C}$ and $80^{\circ} \mathrm{C}$ (Fig. 6).

It is worth noting that the flexure stress -strain curves are different from those obtained in the uniaxial tension tests at the same temperature range; here, the yield drop is not obvious. Also, PMMA did not show a sudden softening after yield in bending as compared to its tension behaviour. This is, probably, due to the nature of the bending as the bending stress is considered as a combination of compressive and tensile stresses.

Table 1 contains the flexure strength of the PMMA at different temperatures at constant crosshead speed of $0.3 \mathrm{~mm} / \mathrm{min}$. The average flexure strength decreased significantly with the increase of temperature, by $85.0 \%$ in the studied temperature range.

The difference of tensile strength $\sigma_{\text {UTS }}$ (Fig. 5) and flexure strength listed in Table 1 can be linked to deformation being nonuniform in bending compared to homogeneous in tension, with the flexural strength representing the stress on the outer layer of the specimen. Moreover, Eq. (3) and Eq. (4) are only valid up to a maximum fibre strain of 5\% [33].

The elastic modulus $E$ of PMMA was computed at different temperatures using the load-deflection responses from the threepoint bending tests using the following formula:

$\boldsymbol{E}=\frac{\boldsymbol{l}^{3}}{4 B \boldsymbol{h}^{3}} \boldsymbol{S}$

where $S$ is the slope (i.e., the tangent) of force-deflection curve between two reference points corresponding to strains of $0.05 \%$ and $0.25 \%$, as described in ISO 178 [24].

In the test, deflection values of 0.09 and $0.34 \mathrm{~mm}$ corresponded

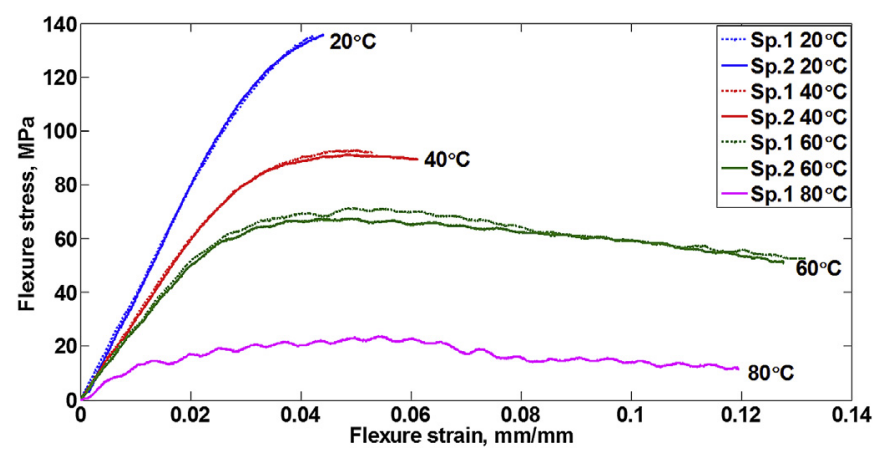

Fig. 6. Flexure stress - flexure strain curves of three-point bending tests at different temperatures.
Table 1

Flexure strength of PMMA at different temperatures.

\begin{tabular}{lllll}
\hline Temperature $\left({ }^{\circ} \mathrm{C}\right)$ & 20 & 40 & 60 & 80 \\
Maximum force $(\mathrm{N})$ & 226.5 & 153.4 & 115.6 & 34.0 \\
Flexure strength $(\mathrm{MPa})$ & 135.9 & 92.0 & 69.3 & 20.4 \\
Fracture strain $(\%)$ & 4.3 & 5.7 & 13.0 & 12.0 \\
\hline
\end{tabular}

to $0.05 \%$ and $0.25 \%$ strains. The resultant values of the elastic modulus of PMMA are given in Table 2; they are highly affected by the temperature. The elastic modulus of PMMA decreased by $73.9 \%$ in the studied temperature range.

\subsection{Identification of parameters of material models}

\subsubsection{Elasto-plastic model}

The elastic parameters of PMMA are represented by the temperature-dependent elastic modulus and the Poisson's ratio $v$ of 0.35 [34]. The methodology of assessing elastic modulus at different temperatures and respective results are given in Section 3. Although there are some differences between the calculated elastic modulus and the reported values [35-39], the authors employed their results.

The plastic data were prepared for different temperatures, using true stress-true strain $\left(\sigma^{\prime}-\varepsilon\right)$ curves. They were calculated from the engineering stress $(\sigma)$ - strain $(\boldsymbol{e})$ curves (Fig. 4), using the wellknown relationships: $\sigma^{\prime}=\sigma(1+e)$ and $\varepsilon=\ln (1+\boldsymbol{e})$.

As discussed, the stress-strain curves of PMMA are characterized by complex behaviour with the elastic response followed by plastic yielding accompanied by initial material strain hardening, with subsequent softening and then final hardening of the materials until fracture (Fig. 4). This behaviour makes it challenging to describe the whole flow curves. Different constitutive material models were suggested to describe such flow curves $[6,7,40]$. The authors examined various models; the most suitable one capable of describing various hardening and softening stages of the flow curves is the constitutive material model after Nasraoui et al. [2]. This constitutive relation was proposed based on the pioneer work of G'sell and Jonas [41] and allows reproducing the main experimental observations of the flow curves detailed previously.

In this model, the flow stress $\sigma_{f}$ as a function of strain $\varepsilon$, strain rate and temperature is expressed by a combination of additive and multiplicative terms [2]:

$$
\begin{aligned}
\boldsymbol{\sigma}_{\boldsymbol{f}}(\boldsymbol{\varepsilon}, \dot{\boldsymbol{\varepsilon}}, \boldsymbol{T})= & \left(1-\frac{\boldsymbol{T}}{\boldsymbol{T}_{\mathbf{g}}}\right)(1-\exp (-\boldsymbol{w \boldsymbol { \varepsilon }}))\left[\boldsymbol{\sigma}_{1} \exp (-\boldsymbol{b} \boldsymbol{\varepsilon})\left(\frac{\dot{\boldsymbol{\varepsilon}}}{\dot{\varepsilon}_{01}}\right)^{\boldsymbol{m}_{1}}\right. \\
& +\boldsymbol{\sigma}_{2} \exp \left(\left(\boldsymbol{h}_{\boldsymbol{o}}\right.\right. \\
& \left.\left.\left.+\boldsymbol{h}_{1} \frac{\boldsymbol{T}-\boldsymbol{T}_{\boldsymbol{o}}}{\boldsymbol{T}_{\boldsymbol{o}}}\right) \boldsymbol{\varepsilon}^{2}\right)\left(1+\left(\frac{\dot{\boldsymbol{\varepsilon}}}{\dot{\varepsilon}_{02}}\right)^{-1}\right)^{-\boldsymbol{m}_{2}}\right]
\end{aligned}
$$

where $\boldsymbol{T}_{\boldsymbol{o}}$ is the reference temperature, taken equal to $298 \mathrm{~K}, \boldsymbol{T}_{\mathbf{g}}$ is the glass transition temperature $(381 \mathrm{~K}), \varepsilon$ is the true strain, $\dot{\varepsilon}_{01}$ is the test strain rate $\left(0.001 \mathrm{~s}^{-1}\right)$ and $\dot{\varepsilon_{0}}$ is the reference strain rate

Table 2

Effect of temperature on elastic modulus of PMMA.

\begin{tabular}{lllll}
\hline Temperature $\left({ }^{\circ} \mathrm{C}\right)$ & 20 & 40 & 60 & 80 \\
Slope $(\mathrm{N} / \mathrm{mm})$ & 40.16 & 31.94 & 38.49 & 10.47 \\
Elastic modulus $(\mathrm{MPa})$ & 5140.5 & 4088.3 & 4926.7 & 1340.2 \\
\hline
\end{tabular}


taken equal to $0.1 \mathrm{~s}^{-1}$. The constants $\boldsymbol{m}_{1}$ and $\boldsymbol{m}_{2}$ are strain-ratesensitivity parameters. The tensile tests were carried out at a constant strain rate of $0.001 \mathrm{~s}^{-1}$; therefore, these two parameters were the same as those calculated by Nasraoui et al. [2]. $\boldsymbol{m}_{1}$ and $\boldsymbol{m}_{2}$ are 0.125 and 0.071, respectively. The other parameters $\boldsymbol{w}, \boldsymbol{b}, \boldsymbol{h}_{0}, \boldsymbol{h}_{1}, \boldsymbol{\sigma}_{1}$ and $\sigma_{2}$ are material-dependant that could be determined from the curve-fitting of the experimental results. $\boldsymbol{m}_{1}$

In Eq. (6), the term $\boldsymbol{\sigma}_{1} \exp (-\boldsymbol{b} \boldsymbol{\varepsilon})\left(\frac{\dot{\boldsymbol{\varepsilon}}}{\dot{\boldsymbol{\varepsilon}}_{01}}\right)^{\cdot \boldsymbol{m}_{1}}$ is used to describe the yield stress and strain softening after the peak stress, whereas the second additive term describes strain-hardening behaviour during plastic deformation. The calibration of the material parameters of this constitutive relation based on our experimental data is described below.

It should be mentioned that the material parameters provided for PMMA based on the model proposed by Nasraoui et al. [2] did not reproduce our tensile stress-strain curves well. The values of these parameters depend on different factors including manufacturing conditions, heat treatment and test conditions. Therefore, these material parameters were used as initial values for an iterative curve-fitting process to reproduce our experimental results (as shown in Fig. 7). A curve-fitting algorithm was used to tune the values of the material parameters in the model proposed by Nasraoui et al. [2] for PMMA to match our experimental data as listed in Table 3. It was found that all the material parameters were temperature-insensitive apart from $\boldsymbol{h}_{1}$. As a result, they were considered as temperature-independent for all test temperatures. The temperature-insensitive material parameters are listed in Table 3 a while the value of temperature-dependent parameter $\boldsymbol{h}_{1}$ is given in Table $3 \mathrm{~b}$. Finally, it can be concluded that the calculated PMMA parameters at quasi-static loading and different temperatures below the glass transition temperature matched the experimental tensile stress-strain curves to a very good extent, as shown in Fig. 7.

\subsubsection{Two-layer viscoplasticity model}

A rheological idealization of the two-layer viscoplasticity model is shown in Fig. 8; it comprises an elastic-plastic network that is parallel with an elastic-viscous (Maxwell model) network. The model describes the combined effect of rate-dependent (elasticviscous network) and rate-independent (elastic-plastic network) material behaviour. The latter demonstrates permanent deformation after load application, whereas the former exhibits permanent deformation under load over time [42]. In the elastic-plastic network, $\boldsymbol{K}_{\boldsymbol{P}}$ is its elastic modulus, $\boldsymbol{\sigma}_{\boldsymbol{y}}$ is the initial yield stress and $\boldsymbol{H}^{\prime}$ is the average slope of the plastic response. In the elasticviscous network, $\boldsymbol{K}_{\boldsymbol{v}}$ is its elastic modulus, $\boldsymbol{A}$ and $\boldsymbol{n}$ are the Norton creep parameters based on the Norton-Hoff law.

The two-layer viscoplasticity model is based on the von-Mises

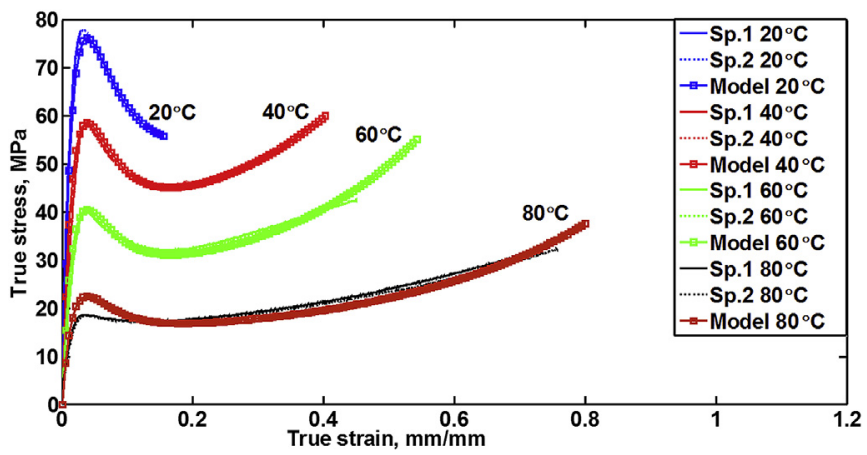

Fig. 7. Description of true stress-true strain curves obtained for PMMA using model proposed by Nasraoui et al. [2] at $0.001 \mathrm{~s}^{-1}$ for different temperatures. yield condition in the elastic-plastic network and the Norton power law (secondary creep) for the viscoplastic behaviour in the elastic-viscous network [43]. The two mechanisms are considered independent, and the total stress $\sigma$ is the sum of the respective stresses $\sigma_{\boldsymbol{v}}$ and $\boldsymbol{\sigma}_{\boldsymbol{p}}$. The model is implemented in ABAQUS and describes the elastic, plastic, and viscous deformations. The elastic component of both networks is defined in terms of linear isotropic elasticity. A parameter $\boldsymbol{f}$ is introduced to define the ratio of the elastic modulus of the elastic network $\left(\boldsymbol{K}_{\boldsymbol{v}}\right)$ to the total (instantaneous) modulus $\left(\boldsymbol{K}_{\boldsymbol{p}}+\boldsymbol{K}_{\boldsymbol{v}}\right)$ as follows [26]:

$\boldsymbol{f}=\frac{\boldsymbol{K}_{\boldsymbol{v}}}{\left(\boldsymbol{K}_{\boldsymbol{p}}+\boldsymbol{K}_{\boldsymbol{v}}\right)}$,

where $\boldsymbol{K}_{\boldsymbol{p}}$ is the elastic modulus at the slowest loading rate and $\boldsymbol{K}_{\boldsymbol{v}}$ is defined by

$\boldsymbol{K}_{\boldsymbol{v}}=\boldsymbol{K}-\boldsymbol{K}_{\boldsymbol{p}}$,

where $\boldsymbol{K}$ is the elastic modulus of the material at the fastest loading rate.

The viscous behaviour of this model is governed by the NortonHoff rate law given by

$\dot{\boldsymbol{\varepsilon}}_{\boldsymbol{v}}^{\boldsymbol{v}}=\boldsymbol{A} \boldsymbol{\sigma}_{\boldsymbol{v}}^{\boldsymbol{n}}$

In Eq. (9), the subscript $\boldsymbol{v}$ denotes quantities in the elasticviscous network alone. This form of the rate law is chosen based on a time-hardening power law for the viscous behaviour and setting $\boldsymbol{m}=0$ [26].

The slope of the plastic response $\boldsymbol{H}^{\prime}$ is defined as the average slope of the stress-strain curve from the beginning of the deviation from elastic response to the yield stress for different loading rates.

Six material parameters need to be identified for the two-layer viscoplasticity model: the elastic properties of the two networks, $\boldsymbol{K}_{\boldsymbol{p}}$ and $\boldsymbol{K}_{\boldsymbol{v}}$; the initial yield $\boldsymbol{\sigma}_{\boldsymbol{y}}$; the hardening parameter $\boldsymbol{H}^{\prime}$; and the Norton-Hoff rate parameters, $\boldsymbol{A}$ and $\boldsymbol{n}$.

In order to define the parameters $\boldsymbol{A}$ and $\boldsymbol{n}$, the long-term (steady-state) relation (in Eq. (9)) of the elastic-viscous network under a constant strain rate is rewritten as:

$\sigma_{v}=\boldsymbol{A}^{-\frac{1}{n}} \dot{\boldsymbol{\varepsilon}}_{\boldsymbol{v}}^{-\frac{1}{n}}$

Under the assumption that the hardening modulus $\boldsymbol{H}^{\prime}$ is negligible compared to the elastic modulus $\left(\boldsymbol{K}_{\boldsymbol{p}} \gg \boldsymbol{H}^{\prime}\right)$, the steady-state response of the overall material is described by

$\sigma_{t}=\boldsymbol{A}^{-\frac{1}{n}} \dot{\boldsymbol{\varepsilon}}_{\boldsymbol{v}}^{-\frac{1}{n}}+\boldsymbol{\sigma}_{\boldsymbol{y}}+\boldsymbol{H}^{\prime} \boldsymbol{\varepsilon}_{\boldsymbol{t}}$

where $\sigma_{t}$ is the total stress for a given total strain $\varepsilon_{t}$.

Identification of the material parameters of this two-layer viscoplasticity model based on an optimization procedure is described in the next section.

\subsection{Optimization procedure for determining viscoplastic material parameters}

In this section, the unknown parameters of the two-layer viscoplasticity model (Eq. (11)) are computed. This model involves three independent parameters: the Norton-Hoff rate parameters, $\boldsymbol{A}$ and $\boldsymbol{n}$, as well as the parameter $\boldsymbol{f}$, with $\boldsymbol{m}$ set equal to zero to represent steady-state secondary creep. These are the only parameters required by ABAQUS software to define the two-layer viscoplasticity model. To identify the constants, an optimization simulation process flow called 'sim-flow' was used. A sim-flow was implemented in Isight software package using ABAQUS 6.13, a data 
Table 3

(a) Temperature-independent parameters for constitutive material model of PMMA at strain rate of $0.001 \mathrm{~s}^{-1}$.

\begin{tabular}{|c|c|c|c|c|c|c|c|c|c|c|}
\hline Parameter & $\begin{array}{l}\mathrm{T}_{\mathrm{g}} \\
(\mathrm{k})\end{array}$ & $\mathrm{w}$ & $\begin{array}{l}\sigma_{1} \\
(\mathrm{MPa})\end{array}$ & $\mathrm{b}$ & $\begin{array}{l}\sigma_{2} \\
(\mathrm{MPa})\end{array}$ & $\mathrm{h}_{\mathrm{o}}$ & $\dot{\varepsilon}_{01}(1 / \mathrm{s})$ & $\mathrm{m}_{1}$ & $\mathrm{~m}_{2}$ & $\dot{\varepsilon}_{02}(1 / \mathrm{s})$ \\
\hline Value & 378 & 38 & 950 & 25 & 140 & 0.85 & 0.001 & 0.125 & 0.071 & 0.1 \\
\hline$T\left({ }^{\circ} \mathrm{C}\right)$ & & & & & 40 & & & 60 & & 80 \\
\hline$h_{1}$ & & & & & 34.6 & & & 16.6 & & 6.64 \\
\hline
\end{tabular}

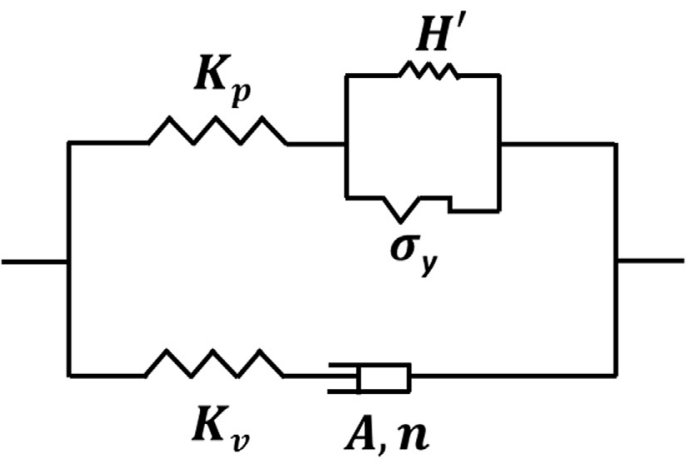

Fig. 8. Rheological idealization of two-layer viscoplasticity model (after [39]).

matching tool, a calculator and a Hooke-Jeeves optimization technique [44], see Fig. 9.

First, an initial guess was used for material parameters in the uniaxial tensile FE model, employing ABAQUS software - generated both the input and output files. Second, the optimization sim-flow was developed (Fig. 9) and each component was configured to define the required data. Then, the material parameters were chosen as the design variables for the optimization algorithm and the history output for the reaction force and displacement of the uniaxial tension model were used for data matching the experimental force-displacement data. The calculator component was used to double the reaction force according to the symmetry boundary conditions used. The data-matching tool played an important role in comparing force-displacement data both for the model and experiments, minimizing the sum of squared differences. The Hooke-Jeeves optimization algorithm was implemented to obtain the material parameters. Lower and upper bounds of all three parameters were defined as optimization constraints. The parameter $\boldsymbol{A}$ was bounded by $1 \mathrm{e}-15$ and 20 , the parameter $\boldsymbol{n}$ was bounded by 1 and 10, and the parameter $\boldsymbol{f}$ was bounded by $1 \mathrm{e}-4$ and 1. The objective function of the optimization process was minimization of the sum of the squared difference of the forces. The obtained calibrated parameters for the studied temperatures are provided in Table 4.

To verify the optimized parameters at each temperature, they were used to simulate the three-point bending test (see below).

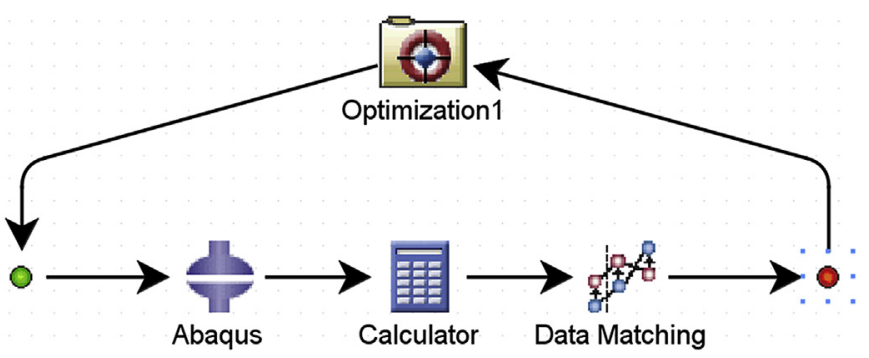

Fig. 9. Optimization sim-flow for calibration of viscoplastic material parameters.

\subsection{Uniaxial tensile FE model}

At the next stage of analysis, FE simulations of the uniaxial tension test were used to examine the two material models used in this work. The comparison of experimental and calculated stressstrain curves of PMMA at different temperatures are presented in Fig. 10. For all the studied temperatures, it was found that the twolayer viscoplasticity formulation described mechanical behaviour of PMMA better. The two formulations exhibited behaviour similar to experiments up to their peaks. However, for the post-yield behaviour, the two-layer viscoplasticity model demonstrated good agreement with the experimental data in contrast to the elasto-plastic one. The elasto-plastic material formulation also overestimated stress values for the elastic responses at lower temperatures $20^{\circ} \mathrm{C}$ and $40{ }^{\circ} \mathrm{C}$, Fig. 10a and b. With temperature increasing to $60{ }^{\circ} \mathrm{C}$, the elasto-plastic model demonstrated behaviour similar to that of the two-layer viscoplasticity in the elastic range and up to the ultimate tensile stress. However, for $80^{\circ} \mathrm{C}$, the elasto-plastic model overestimated the ultimate tensile stress.

Various mesh refinements were examined to investigate their effect on softening behaviour of the elasto-plastic model; however, no significant changes were found with a steep drop in the stress level after reaching the ultimate tensile stress level (Fig. 10).

In contrast, the two-layer viscoplasticity model showed good agreement with the experimental data for all the temperatures for the entire curves. However, it slightly overestimated both the ultimate tensile stress $\sigma_{U T S}$ and the respective strain for PMMA curves at $40{ }^{\circ} \mathrm{C}, 60{ }^{\circ} \mathrm{C}$ and $80^{\circ} \mathrm{C}$.

When the two-layer material formulation was used to model the uniaxial tension test at $20^{\circ} \mathrm{C}$, there was no drop in the stress level, see Fig. 10a. This was reflected in a uniform distribution of von Mises stress at the end of simulation without any drop in the stress level (Fig. 11b), in contrast to apparent stress localization predicted with the elasto-plastic formulation (Fig. 11a).

The von Mises stress at $80{ }^{\circ} \mathrm{C}$ calculated with the two-layer viscoplasticity model (Fig. 12) showed uniform distribution at the peak load, but a different character at the end of simulations with large global deformations.

\subsection{Three-point bending FE model}

The two material formulations were further used to simulate three-point bending tests. After their validation process with the tension tests, the same material parameters at each temperature were used for bending. The load-deflection curves of PMMA

Table 4

Identified material parameters for PMMA two-layer viscoplasticity model at four different temperatures.

\begin{tabular}{llll}
\hline & $\mathrm{A}$ & $\mathrm{n}$ & $\mathrm{f}$ \\
\hline $20{ }^{\circ} \mathrm{C}$ & 0.0002 & 4 & 0.50005 \\
$40^{\circ} \mathrm{C}$ & 0.069 & 1.22 & 0.50005 \\
$60^{\circ} \mathrm{C}$ & 0.2 & 1 & 0.50005 \\
$80{ }^{\circ} \mathrm{C}$ & 0.6 & 1 & 0.50005 \\
\hline
\end{tabular}


a)

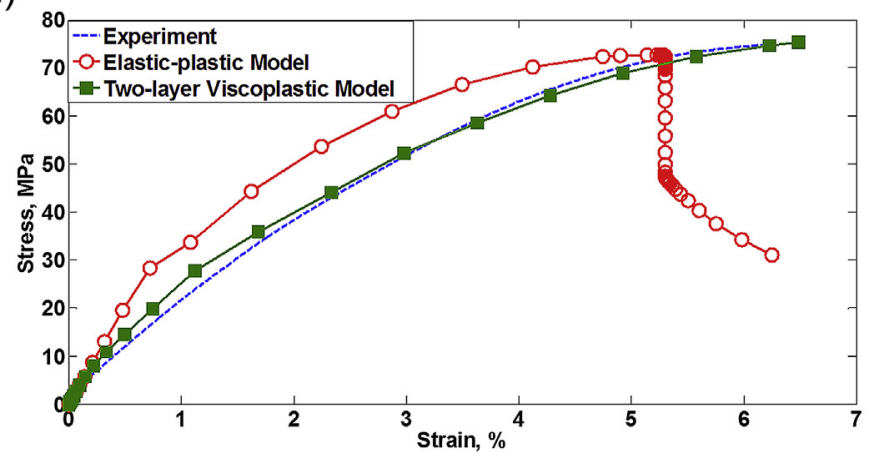

c)

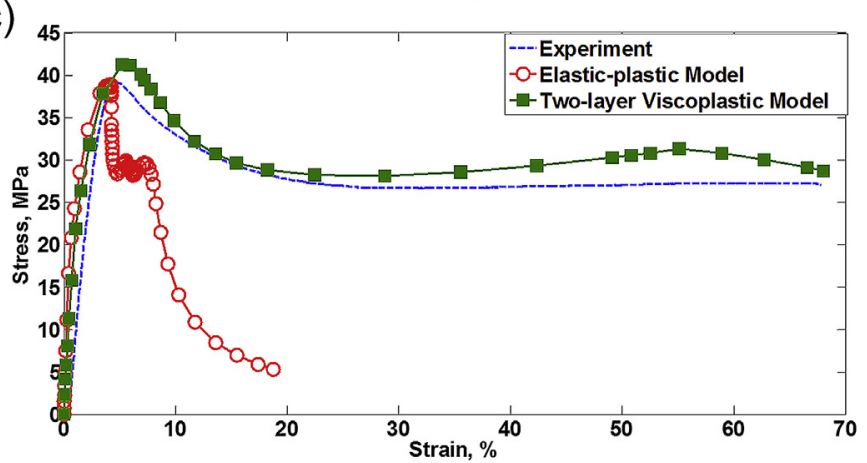

b)

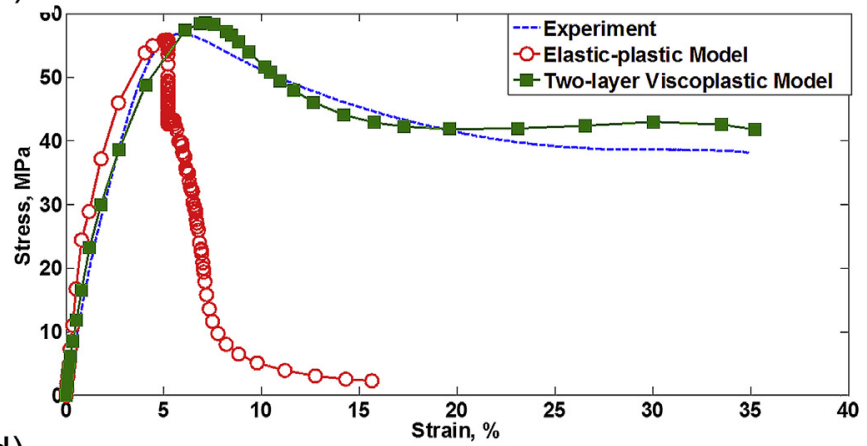

d)

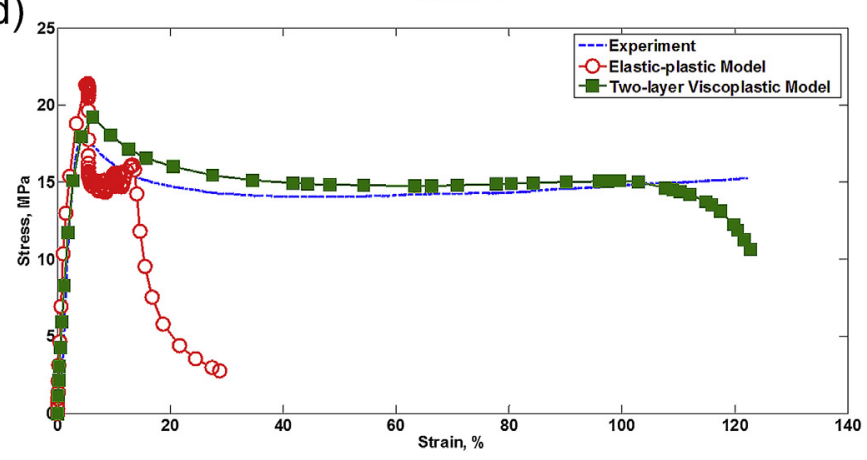

Fig. 10. Experimental and numerical stress-strain curves for PMMA under uniaxial tension for (a) $20^{\circ} \mathrm{C}$; (b) $40{ }^{\circ} \mathrm{C}$; (c) $60{ }^{\circ} \mathrm{C}$; (d) $80{ }^{\circ} \mathrm{C}$.
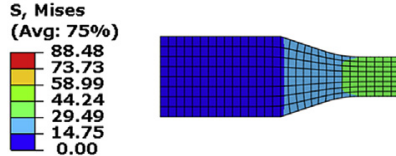

a)
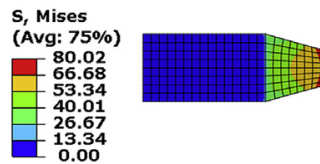

0.00

b)

Fig. 11. Distribution of von Mises stress in PMMA specimen in uniaxial tension at $20^{\circ} \mathrm{C}$ (a) elasto-plastic model (strain 6.25\%); (b) two-layer viscoplasticity model at end of simulations (strain 6.49\%).

obtained with these FE simulations are compared with the experimental results at different temperatures in Fig. 13. Generally, both models showed good agreement with the experimental results, but the performance of the two-layer material model was better. Apparently, the elasto-plastic material model provided acceptable results up to a certain level of deformation only. Similar to the case of the tension tests, the elasto-plastic material model overestimated the forces for all the simulated conditions. It should be noted that the elasto-plastic model predicted post yielding behaviour of specimens tested at $20^{\circ} \mathrm{C}, 40^{\circ} \mathrm{C}$, and $60^{\circ} \mathrm{C}$ very well. In this loading regime, PMMA experiences low levels of stress and deformation compared to the uniaxial tension test, and, as a result, deformations in the specimen did not go beyond the limitations of the model.

Although the two-layer material formulation showed some deviations from the experimental data, it captured the general load-deflection behaviour better. Both models overestimated the peak load in all the simulations, but the two-layer material model
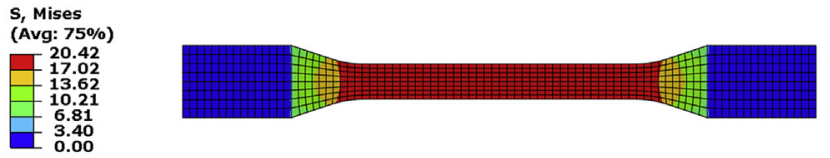

(a)
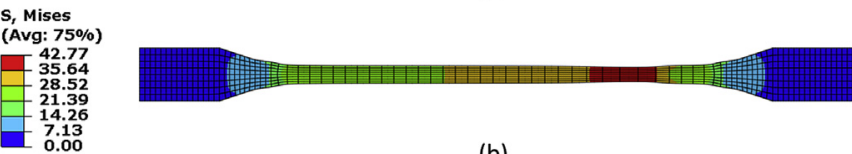

(b)

Fig. 12. Distribution of von Mises stress in PMMA specimen in uniaxial tension using two-layer viscoplasticity material model at $80^{\circ} \mathrm{C}$ : (a) at peak stress level (strain $6.29 \%$ ); (b) at end of simulation (strain 122.7\%).

followed the load-deflection profile more closely.

Distributions of typical von Mises stress at the peak load for three-point bending specimens tested at $20^{\circ} \mathrm{C}$ and $80^{\circ} \mathrm{C}$ are shown in Fig. 14 for the two models used. The two-layer material model demonstrated a higher level of stresses compared to the elastoplastic material model, and a larger deflection at peak load.

\section{Conclusions}

An experimental study was performed to examine the influence of the temperature on mechanical behaviour of PMMA using uniaxial tension and three-point bending. Additionally, a numerical analysis was introduced to identify the parameters of two different material formulations for PMMA, namely, elasto-plastic and twolayer viscoplasticity constitutive material models. The following conclusions were drawn: 
a)

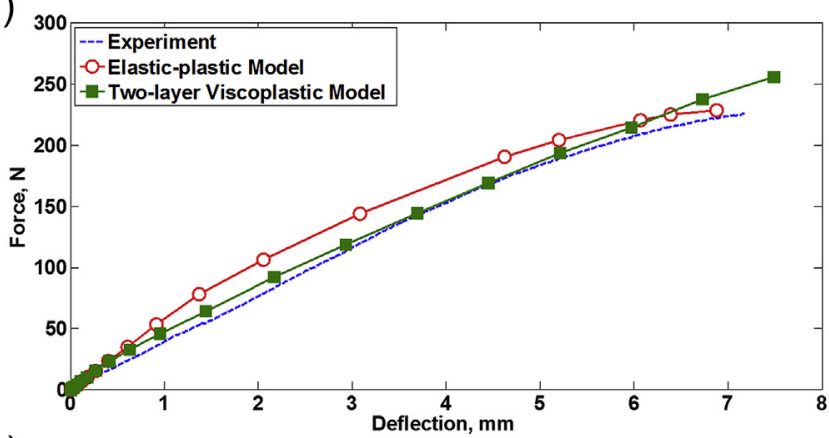

b)
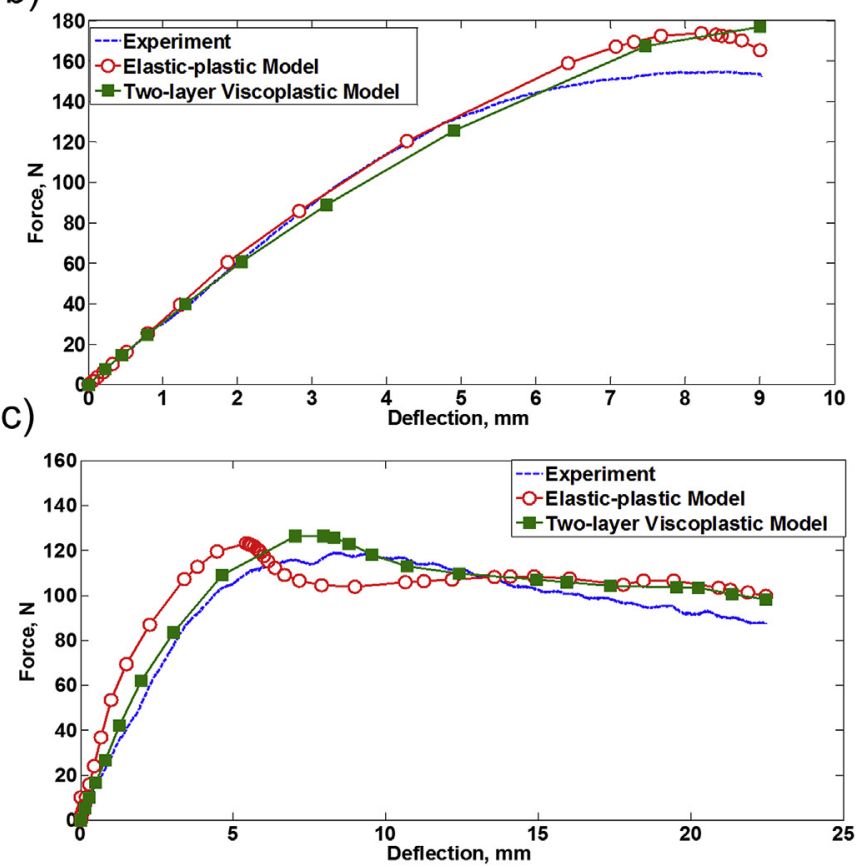

Fig. 13. Experimental and numerical force-displacement behaviour of PMMA specimen in three-point bending: (a) $20^{\circ} \mathrm{C}$; (b) $40^{\circ} \mathrm{C}$; (c) $60{ }^{\circ} \mathrm{C}$.

- The temperature rise significantly affected the elastic modulus, yield stress, ultimate tensile stress and strain at fracture of PMMA.

- PMMA demonstrated quasi-brittle fracture at the room temperature and super plastic-behaviour $(\varepsilon>110 \%)$ at $80^{\circ} \mathrm{C}$.

- The flow curves of PMMA were successfully described with the employed material models and their parameters were quantified. The optimal parameters of the two-layer viscoplasticity material model were defined with a developed sim-flow optimization tool.

- The two-layer viscoplasticity material model demonstrated better agreement with the experimental data compared to the elasto-plastic material model through the verification using the uniaxial tension data for PMMA.

- The FE simulations with the two material models were validated using the three-point bending data. The two-layer viscoplasticity model demonstrated good overall agreement with these experimental results, while the elasto-plastic material model showed acceptable results.

\section{Acknowledgement}

The authors would like to show their gratitude to Dr Khaled Al-

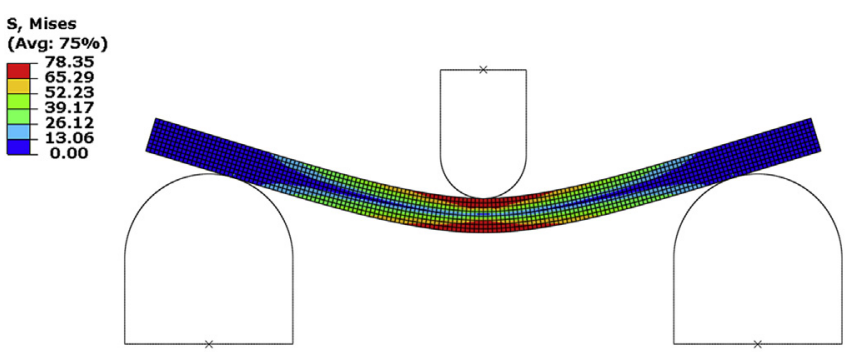

(a)

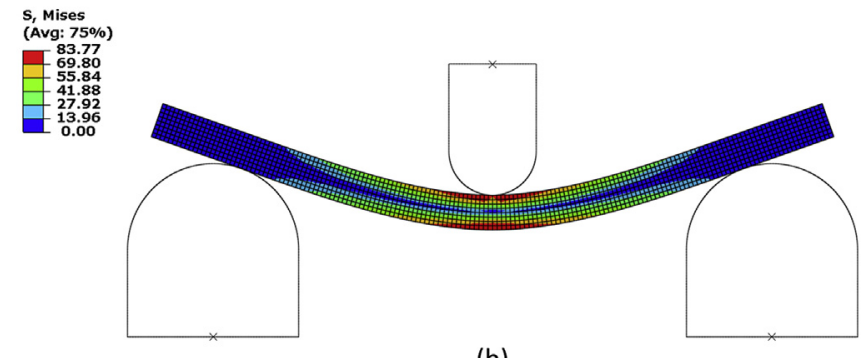

(b)

Fig. 14. Distribution of von Mises stress in PMMA specimen in three-point bending at peak load at $20^{\circ} \mathrm{C}$ : (a) elastic-plastic model; (b) two-layer viscoplasticity model.

Ghefaili and Eng. Shajahan Khan at the Higher Institute for Plastics Fabrication (Riyadh, KSA) for assisting in production of the PMMA samples.

\section{References}

[1] J. Rösler, H. Harders, M. Bäker, Mechanical behaviour of polymers, in: J. Rösler, H. Harders, M. Bäker (Eds.), Mechanical Behaviour of Engineering Materials Metals, Ceramics, Polymers, and Composites, Springer, Berlin, 2007.

[2] M. Nasraoui, P. Forquin, L. Siad, A. Rusinek, Influence of strain rate, temperature and adiabatic heating on the mechanical behaviour of poly-methylmethacrylate: experimental and modelling analyses, Mat. Des. 37 (2012) 500-509.

[3] A.D. Mulliken, M.C. Boyce, Mechanics of the rate-dependent elastic-plastic deformation of glassy polymers from low to high strain rates, Int. J. Solids Struct. 43 (2006) 1331-1356.

[4] W. Chen, G. Ravichandran, Dynamic compressive failure of glass ceramic under lateral confinement, J. Mech. Phys. Solids 45 (1997) 1303-1328.

[5] A.M. Mimaroglu, O.F. Yenihayat, A. Celebi, The influence of the thermal history, strain rate and sample geometry on the deformation behaviour of polymers: use of the thermovision technique, Mat. Des. 16 (1995) 199-203.

[6] E.M. Arruda, M.C. Boyce, R. Jayachandran, Effects of strain rate, temperature and thermomechanical coupling on the finite strain deformation of glassy polymers, Mech. Mat. 19 (1995) 193-212.

[7] J. Richeton, S. Ahzi, K.S. Vecchio, F.C. Jiang, R.R. Adharapurapu, Influence of temperature and strain rate on the mechanical behavior of three amorphous polymers: characterization and modeling of the compressive yield stress, Int. J. Solids Struct. 43 (2006) 2318-2335.

[8] S.C. Chou, K.D. Robertson, J.H. Rainey, The effect of strain rate and heat developed during deformation on the stress-strain curve of plastics, Expe. Mech. 13 (1973) 422-432.

[9] B.J. Briscoe, R.W. Nosker, The flow stress of high density polyethylene at high rates of strain, Polym. Commun. 26 (1985) 307-308.

[10] J. Jancar, R.S. Hoy, E. Jancarova, J. Zidek, Effect of temperature, strain rate and particle size on the yield stresses and post-yield strain softening of PMMA and its composites, Polymer 63 (2015) 196-207.

[11] S. Raha, P.B. Bowden, Birefringence of plastically deformed poly(methyl methacrylate, Polymer 13 (1972) 174.

[12] E.M. Arruda, M.C. Boyce, Evolution of plastic anisotropy in amorphous polymers during finite straining, Int. J. Plast. 9 (1993) 697-720.

[13] M.C. Boyce, D.M. Parks, A.S. Argon, Large inelastic deformation of glassy polymers, Part I: rate dependent constitutive model, Mech. Mat. 7 (1988) $15-33$.

[14] B.E.K. Singh, Material Characterization, Constitutive Modeling and Finite Element Simulation of Polymethyl Methacrylate (PMMA) for Applications in Hot Embossing, Mecanical Engineering Department, The Ohio State University, Ohio, USA, 2011, p. 202.

[15] R.E. Robertson, Theory for plasticity of glassy polymers, J. Chem. Phys. 44 (1966) 3950.

[16] A.S. Argon, Theory for low-temperature plastic-deformation of glassy 
polymers, Philos. Mag. 28 (1973) 839-865.

[17] R.N. Haward, G. Thackray, Use of a mathematical model to describe isotherma stress-strain curves in glassy thermoplastics, Proc. R. Soc. Lond. Ser. a-Mathematical Phys. Sci. 302 (1968) 453.

[18] M. Doi, S.F. Edwards, Dynamics of concentrated polymer systems Part 3-the constitutive equation, J. Chem. Soc. Faraday Trans. 2 (74) (1978) 1818-1832.

[19] M. Doi, A constitutive equation derived from the model of Doi and Edwards for concentrated polymer solutions and polymer melts, J. Polym. Sci. Part B Poly. Phys. 18 (1980) 2055-2067.

[20] S.F. Edwards, T. Vilgis, The effect of entanglements in rubber elasticity, Polymer 27 (1986) 483-492.

[21] ISO 8257-2, Plastics Poly(methyl Methacrylate) (PMMA) Moulding and Extrusion Materials - Part 2: Preparation of Test Specimens and Determination of Properties Paperback, ISO, 2001.

[22] BSI 2782-3, Methods of Testing Plastics. Mechanical Properties. Tensile Strength, Elongation and Elastic Modulus, BSI, 1976.

[23] ISO 527-1, Plastics Determination of Tensile Properties - Part 1: General Principles, ISO, 2012.

[24] ISO 178, Plastics Determination of Flexural Properties, ISO, 2010.

[25] N. Nuno, R. Groppetti, N. Senin, Static coefficient of friction between stainless steel and PMMA used in cemented hip and knee implants, Clin. Biomech. 21 (2006) 956-962.

[26] ABAQUS, ABAQUS Documentation, Dassault Systèmes, Dassault Systèmes, Providence, RI, USA, 2013.

[27] A.D. Mulliken, M.C. Boyce, Mechanics of the rate-dependent elastic-plastic deformation of glassy polymers from low to high strain rates, Int. J. Solids Struct. 43 (2006) 1331-1356.

[28] N. Brown, I.M. Ward, Load drop at the upper yield point of a polymer, J. Polym. Sci. Part B, Polym. Phys. 6 (1968) 607-620.

29] E. El-Magd, in: G.E. Totten, L. Xie, K. Funatani, M. Dekker (Eds.), Modeling and Simulation of Mechanical Behavior, Modeling and Simulation for Material Selection and Mechanical Design, New York, USA, 2004.

[30] W.R. Blumenthal, C.M. Cady, M.F. Lopez, G.T.G. III, D.J. Idar, Influence of temperature and strain rate on the compressive behavior of PMMA and polycarbonate polymers, in: M.D. Furnish, N. Thadhani, Y. Horie (Eds.), $12^{\text {th }}$ APS Topical Conference on Shock Compression of Condensed Matter American
Institute of Physics Press, Woodbury, New York, Atlanta, GA, 2001.

[31] M. Eftekhari, A. Fatemi, Tensile, creep, and fatigue behaviors of short fiber reinforced polymer composites at elevated temperatures: a literature survey Fatigue frac. Eng. Mat. 38 (2015) 1395-1418.

[32] M. Eftekhari, A. Fatemi, Tensile behavior of thermoplastic composites including temperature, moisture, and hygrothermal effects, Polym. Test. 51 (2016) 151-164

[33] R. Brown, Handbook of Polymer Testing Short-term Mechanical Tests, Rapra Technology Limited, Shropshire, UK, 2002.

[34] J. Richeton, S. Ahzi, K.S. Vecchio, F.C. Jiang, A.M. a, Modeling and validation of the large deformation inelastic response of amorphous polymers over a wide range of temperatures and strain rates, Int. J. Solids Struct. 44 (2007) $7938-7954$.

[35] C.A. Harper, Handbook of Plastic Processes, John Wiley \& Sons, 2005.

[36] C.A. Harper, E.M. Petrie, Plastics Materials and Processes, John Wiley \& Sons, 2003.

[37] D.W. van Krevelen, Properties of Polymers, Elsevier, 2003.

[38] T. Jin, X. Niu, G. Xiao, Z. Wang, Z. Zhou, G. Yuan, X. Shu, Effects of experimental variables on PMMA nano-indentation measurements, Polym. Test. 41 (2015) $1-6$.

[39] J. Menčík, L.H. He, J. Němeček, Characterization of viscoelastic-plastic properties of solid polymers by instrumented indentation, Polym. Test. 30 (2011) 101-109.

[40] G. Jo, J. Fu, H.E. Naguib, Constitutive modeling for mechanical behavior of PMMA microcellular foams, Polymer 46 (2005) 11896-11903.

[41] C. G'sell, J.J. Jonas, Determination of the plastic behavior of solid polymers at constant true strain rate, J. Mat. Sci. 14 (1979) 583-591.

[42] J.J. Kang, A.A. Becker, W. Sun, Determination of elastic and viscoplastic material properties obtained from indentation tests using a combined finite element analysis and optimization approach, Proc. IMechE, Part L J. Mat. Des. Appl. 229 (2015) 175-188.

[43] C.D. Cassino, Characterization and Development of General Material Models for Use in Modeling Structures Bonded with Ductile Adhesives (Ph.D. thesis), Faculty of Virginia Polytechnic Institute and State University Blacksburg, Virginia, 2005

[44] V. Isight, 3.5.3, User's Guide, Simulia, 2009. 